\title{
The effectiveness of ultrasonography in verifying the placement of a nasogastric feeding tube in patients with low consciousness at an emergency center
}

\author{
HM Kim ${ }^{1 *}$, BH So ${ }^{1}$, WJ Jeong ${ }^{1}$, SM Choi ${ }^{2}$, KN Park ${ }^{3}$ \\ From 9th WINFOCUS World Congress on Ultrasound in Emergency and Critical Care \\ Hong Kong. 6-9 November 2013
}

\section{Background and objective}

This study was designed to compare the effectiveness of using auscultation, $\mathrm{pH}$ measurements of gastric aspirates, and ultrasonography as physical examination methods to verify nasogastric tube placement in emergency room patients with low consciousness who require nasogastric tube insertion.

\section{Patients and methods}

The study included 47 patients who were all over 18 years of age. In all patients, tube placement was verified by chest $\mathrm{x}$-rays. Auscultation, $\mathrm{pH}$ analysis of gastric aspirates, and ultrasonography were conducted on each patient in random order. The mean patient age was 57.62 \pm 17.24 years, and 28 males $(59.6 \%)$ and 19 females (40.4\%) were included. The nasogastric tube was inserted by an emergency room resident. For $\mathrm{pH}$ testing, gastric aspirates were dropped onto litmus paper, and the resulting color of the paper was compared with a reference table. Ultrasonography was performed by an emergency medicine specialist, and the chest $\mathrm{x}$-ray examination was interpreted by a different emergency medicine specialist who did not conduct the ultrasonography test. The results of the auscultation, gastric aspirate $\mathrm{pH}$, and ultrasonography examinations were compared with the results of the chest $\mathrm{x}$-ray examination.

\section{Results}

The sensitivity and specificity were $100 \%$ and $33.3 \%$, respectively, for auscultation and $86.4 \%$ and $66.7 \%$, respectively, for ultrasonography. Kappa values were the highest for auscultation at 0.484 compared to chest $\mathrm{x}$-rays, followed by 0.299 for ultrasonography and 0.130 for $\mathrm{pH}$ analysis of the gastric aspirate. However, the $\mathrm{p}$ value for the $\mathrm{pH}$ method was $0.182(>0.05)$.

\section{Conclusion}

Ultrasonography is useful for confirming the results of auscultation after nasogastric tube insertion among patients with low consciousness at an emergency center. When ultrasound findings suggest that the nasogastric tube placement is not gastric, additional radiographic examinations should be performed.

\section{Authors' details}

'Department of Emergency Medicine, College of Medicine, The Catholic University of Korea, St. Vincent's Hospital, Suwon, Korea. ${ }^{2}$ Department of Emergency Medicine, College of Medicine, The Catholic University of Korea, St. Mary's Hospital, Uijeongbu, Korea. ${ }^{3}$ Department of Emergency Medicine, College of Medicine, The Catholic University of Korea, St. Mary's Hospital, Seoul, Korea.

Published: 31 January 2014

doi:10.1186/2036-7902-6-S1-A16

Cite this article as: Kim et al:: The effectiveness of ultrasonography in verifying the placement of a nasogastric feeding tube in patients with low consciousness at an emergency center. Critical Ultrasound Journal 2014 6(Suppl 1):A16. 